\title{
Genetic correlations and reaction norms in wing pattern of the tropical butterfly Bicyc/us anynana
}

\author{
JACK J. WINDIG* \\ Institute of Evolutionary and Ecological Sciences, Section of Evolutionary Biology, University of Leiden, Schelpenkade \\ $14 A, 2313 Z T$ Leiden, the Netherlands
}

\begin{abstract}
Genetic correlations $\left(r_{\mathrm{g}}\right)$ within and across environments, were determined in the tropical, dry-wet seasonal polyphenic butterfly Bicyclus anynana, over four temperatures, for larval DEVELOPMENT time (plastic), pupal WEIGHT (less plastic) and two wing pattern characters: SEASONAL FORM (plastic) and THERMAL FORM (less plastic). The $r_{\mathrm{g}} \mathrm{s}$ for SEASONAL FORM were weak, making it relatively independent across seasons. The $r_{\mathrm{g}} \mathrm{s}$ for WEIGHT were intermediate between THERMAL and SEASONAL FORM. Negative $r_{\mathrm{g}} \mathrm{s}$ were present for DEVELOPMENT. The reaction norms for DEVELOPMENT time clearly crossed at an intermediate temperature, whereas the others did not. This implies that selection for fast growers in one season has an opposite effect in the other season. $r_{\mathrm{g}} \mathrm{s}$ between WEIGHT and the other characters remained constant over temperatures, as did the correlation between DEVELOPMENT and THERMAL FORM. Both the correlation between DEVELOPMENT and SEASONAL FORM and between THERMAL FORM and SEASONAL FORM showed a sign change across temperatures. Reaction norms confirmed and clarified these sign changes. The sign change for DEVELOPMENT-SEASONAL FORM might reflect underlying physiological processes. The sign change for THERMAL FORM-SEASONAL FORM might be caused by different trade-offs in the different seasons.
\end{abstract}

Keywords: genetic correlations, jackknife, Lepidoptera, plasticity, reaction norms, wing pattern.

\section{Introduction}

Genetic covariance, or its standardized form genetic correlation $\left(r_{\mathrm{g}}\right)$, can have a strong influence on the result of natural selection and consequently play an important role in multivariate evolution (Lande, 1982). $r_{\mathrm{g}} \mathrm{s}$ between two characters reflect the number of genes, or linked genes, that influence both characters, and also the distribution of relative strength of effects of the genes (Falconer, 1989). $r_{\mathrm{g}} \mathrm{s}$ tend to be stronger between characters that are developmentally related (e.g. Cowley \& Atchley, 1990) and/or functionally related (e.g. Kingsolver \& Wiernasz, 1991). Negative $r_{\mathrm{g}} \mathrm{s}$ are expected in the case of trade-offs (Stearns, 1992). $r_{\mathrm{g}} \mathrm{s}$ between similar characters frequently differ (reviewed in Stearns et al., 1991), both between species (e.g. Lofsvold, 1986), and between populations (e.g. Dingle et al., 1988).

\footnotetext{
*Present address and correspondence: Department of Biology, University of Antwerp (UIA), Universiteitsplein 1, B-2610, Wilrijk, Belgium.
}

Within a single organism $r_{\mathrm{g}} \mathrm{s}$ can also differ considerably between environments (e.g. Giesel et al., 1982; Service \& Rose, 1985; Gebhardt \& Stearns, 1988; Holloway et al., 1990). In other words the genetic relationship between characters can be plastic. Plasticity can be analysed with the help of $r_{\mathrm{g}} \mathrm{s}$. In this case it is not $r_{\mathrm{g}} \mathrm{s}$ between two characters that are used, but $r_{\mathrm{g}} \mathrm{s}$ between the expressions of a single character in two environments (Via \& Lande, 1985). The $r_{\mathrm{g}}$ between two characters, $a$ and $b$, indicates the strength of the simultaneous effect on $b$, when selection occurs on $a$. The $r_{\mathrm{g}}$ within a character in two environments, $x$ and $y$, indicates the effect on the character in $y$, when selection occurs in $x$.

Via \& Lande (1985) used the relationship between genotype by environment interaction $(\mathrm{g} \times \mathrm{e})$ and the $r_{\mathrm{g}}$ between environments to analyse plasticity. They modelled the evolutionary trajectory of a (plastic) character when different optima are favoured in two environments, i.e. selection for plasticity. The evolution towards a joint optimum can be slowed down by strong 
correlations, but only correlations of +1 or -1 (no $\mathrm{g} \times \mathrm{e}$ ) can prevent the realization of a genotype which is optimal in both environments. $\mathrm{G} \times \mathrm{e}$ has played an important role in the analysis of plasticity (Schlichting, 1976; Scheiner \& Lyman, 1989). Many studies have estimated $\mathrm{g} \times \mathrm{e}$ (e.g. Zuberi \& Gale, 1976; Groeters \& Dingle, 1987; Newman, 1988; Wade, 1990; Hughes, 1992 ) in order to examine the evolutionary potential of organisms in relation to variable environments.

One $r_{\mathrm{g}}$ within a character between two environments may not be enough to characterize plasticity. Many plastic characters show continuous responses to changes in the environment. Even discrete responses, or discrete phenotypes caused by discrete environments, often have underlying continuous reaction norms (Windig, 1992). Reaction norms can be used to analyse such characters (Thompson, 1991). The effects of reaction norms on $r_{\mathrm{g}} \mathrm{s}$ were modelled by de Jong $(1989,1990 a, b)$.

Genetic correlations within one environment between two characters can also be reflected in reaction norms. Reaction norms can also be presented as plots of one character against another (Stearns, 1992) with different genotypes and environments indicated. In such plots $r_{\mathrm{g}} \mathrm{s}$ are reflected by regression lines through the points within one environment. These regression lines will run parallel if $r_{\mathrm{g}} \mathrm{s}$ do not change over environments. Their slopes will be different if the $r_{\mathrm{g}} \mathrm{s}$ change.

The aim of this study is to analyse a system, which is adaptively plastic, with the help of reaction norms and $r_{\mathrm{g}} \mathrm{s}$. The study system used is the tropical butterfly Bicyclus anynana which has different, temperature induced, wing patterns in the dry and wet season (Brakefield \& Reitsma, 1991). A continuous range of dry to wet wing patterns can be obtained in the laboratory by raising the butterflies at different temperatures (Windig, 1992). The genetics of the wing pattern changes across temperatures and there is substantial genetic variation for the plasticity itself (Windig, 1993, 1994). Artificial selection on one wing character (size of an eyespot) influences many other characters at the same temperature (Holloway et al., 1993a). In this study the following questions will be addressed.

1 What form do the bundles of reaction norms have? 2 Are the $r_{\mathrm{g}} \mathrm{s}$ within characters, between temperatures, significant? Are there negative $r_{\mathrm{g}} \mathrm{s}$ ?

3 Are the $r_{\mathrm{g}} \mathrm{s}$ between characters, within temperatures, significant? If so, are they constant, or do they change sign between temperatures?

4 Are the estimated $r_{\mathrm{g}} \mathrm{s}$ consistent with the reaction norms?

\section{Materials and methods}

\section{Study system and rearing}

Bicyclus is a species-rich genus of butterflies (Condamin, 1973) and occurs throughout Africa south of the Sahara. Most members display a conspicuously dry-wet season polyphenism. The wing pattern of wet season forms has conspicuous elements (e.g. eyespots and a white median band) (Windig et al., 1994). These elements are thought to deflect predator attacks away from the body, or to disrupt the shape of the wing. The wing pattern of the dry season form is more uniformly brown and thought to be cryptic against brown, dead leaves (Brakefield \& Larsen, 1984). The butterflies only reproduce in the wet season. At the end of the wet season, dry season butterflies appear, mainly resting on the ground covered with dead brown leaves. In the next wet season they are the first reproducing generation (Brakefield \& Reitsma, 1991). Bicyclus anynana is one of the most widespread members of the genus, and occurs in savannah and at the edges of forests.

A laboratory population of butterflies originated from a sample of over 80 gravid females from a population at Nkatha Bay, Malawi, with a highly seasonal climate. A total of 43 pairings in two experiments were derived from this stock. Initially 21 families were obtained; the experiment was then repeated once to obtain more families. Males and females were allowed to pair only once, so all families consisted of full-sibs. Offspring of each family were split over four temperatures: $17^{\circ} \mathrm{C}$ (dry season temperature), $28^{\circ} \mathrm{C}$ (wet season temperature) and $20^{\circ} \mathrm{C}$ and $23^{\circ} \mathrm{C}$ (intermediate temperatures). The number reared successfully differed between experiments and temperatures (Table 1). Relative humidity was around 90 per cent and the light/dark regime was $12 / 12 \mathrm{~h}$ in all temperatures. Larvae were raised on a mixture of one of their natural food plants (the grass Oplismenus compositus) and young maize (Zea mays). Details of the breeding procedure are described by Windig (1994).

\section{Measurements}

Measurements of the wing pattern were made with an image analyser (Windig, 1991), to an accuracy of around 1 per cent. Eight characters of the wing pattern were measured. They were selected in the closely related $B$. safitza for efficiency in indicating the wing pattern and the accuracy of their measurement (for details see Windig, 1991, 1993).

To reduce the number of characters to be evaluated a principal component analysis (PCA) was used to summarize all wing characters into two components 
Table 1 Number of butterflies (Bicyclus anynana), mean number per family and total number of families (in parentheses) for temperatures, sexes and experiments

\begin{tabular}{|c|c|c|c|c|c|c|c|c|}
\hline \multirow[b]{3}{*}{ Temperature } & \multicolumn{4}{|c|}{ Experiment 1} & \multicolumn{4}{|c|}{ Experiment 2} \\
\hline & \multicolumn{2}{|r|}{ Males } & \multicolumn{2}{|c|}{ Females } & \multicolumn{2}{|r|}{ Males } & \multicolumn{2}{|c|}{ Females } \\
\hline & $n$ & Mean (Fams) & $n$ & Mean (Fams) & $n$ & Mean (Fams) & $n$ & Mean (Fams) \\
\hline \multicolumn{9}{|l|}{$17^{\circ}$} \\
\hline Reared & 78 & $4.5(18)$ & 60 & $4.0(15)$ & 125 & $7.4(17)$ & 115 & $6.7(17)$ \\
\hline Used & 75 & $5.0(15)$ & 58 & $4.5(13)$ & 121 & $8.1(15)$ & 111 & $7.4(15)$ \\
\hline \multicolumn{9}{|l|}{$20^{\circ}$} \\
\hline Reared & 73 & $5.2(14)$ & 74 & $5.7(13)$ & 151 & $10.1(15)$ & 145 & $9.7(15)$ \\
\hline Used & 72 & $5.5(13)$ & 73 & $6.1(12)$ & 151 & $10.1(15)$ & 145 & $9.7(15)$ \\
\hline \multicolumn{9}{|l|}{$23^{\circ}$} \\
\hline Reared & 67 & $5.6(12)$ & 71 & $5.9(12)$ & 259 & $11.8(22)$ & 257 & $12.2(21)$ \\
\hline Used & 65 & $6.5(10)$ & 67 & $6.7(10)$ & 254 & $12.7(20)$ & 254 & $12.7(20)$ \\
\hline \multicolumn{9}{|l|}{$28^{\circ}$} \\
\hline Reared & 108 & $5.4(20)$ & 116 & $5.5(21)$ & 298 & $14.9(20)$ & 273 & $13.7(20)$ \\
\hline Used & 107 & $5.6(19)$ & 112 & $5.9(19)$ & 294 & $16.3(18)$ & 269 & $14.9(18)$ \\
\hline
\end{tabular}

Reared, total number of butterflies reared; Used, familes that were (sometimes) considered outliers subtracted.

Fig. 1 Wing pattern traits measured, and composition of principal components, in butterflies Bicyclus anynana.

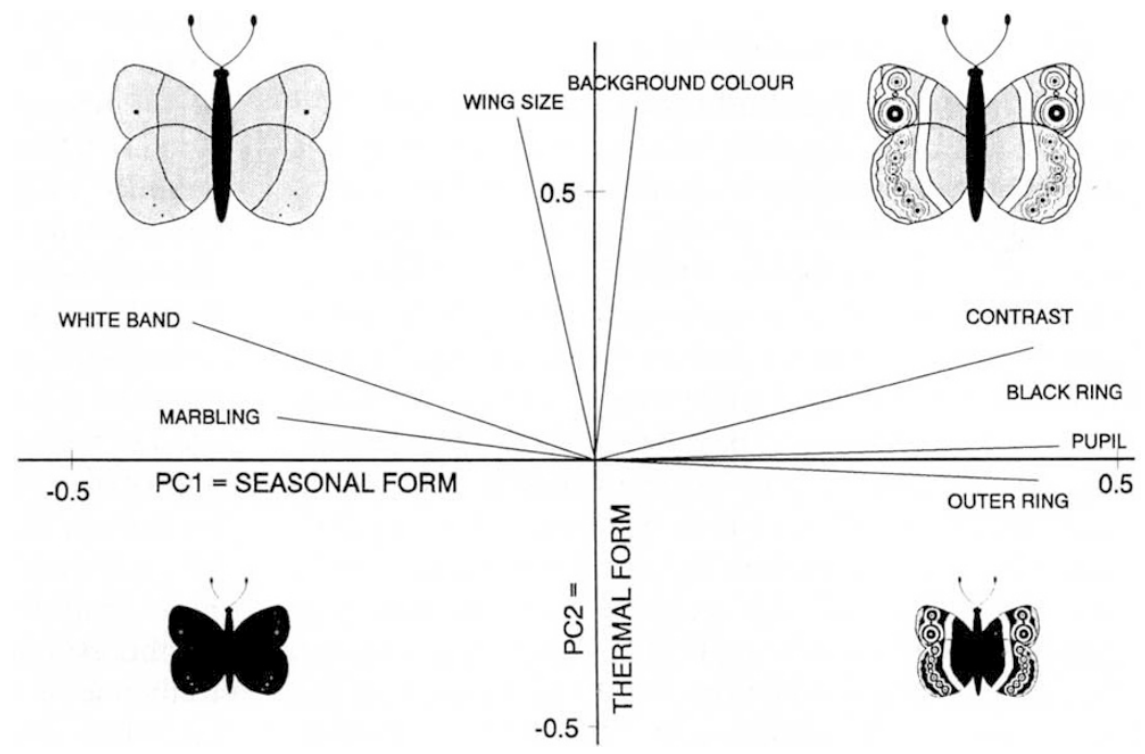

(Fig. 1). Characters were transformed to normal distributions where necessary (Windig, 1994) and standardized before PCA was applied. Plastic characters mainly contributed to the first principal component (PC1, 47 per cent) which can be interpreted as an index of seasonal form (henceforth SEASONAL FORM). Wing size and colour were the most important characters for the second component (PC2, 32 per cent), which can be interpreted as an index of thermal form and sex (henceforth THERMAL FORM), the small, dark butterflies (e.g. males) having lower values
(Windig, 1992). Small dark forms probably need less time to heat up and can fly faster and at lower temperatures (Dennis, 1993).

In addition to the wing characters, two other characters were measured. Larval development time (henceforth DEVELOPMENT) was measured as the number of days from egg hatching till emergence of the butterflies from pupae and was log transformed to obtain a normal distribution. Pupae were weighed, with an accuracy of $10^{-4} \mathrm{~g}, 2$ days after pupation when their cuticle had fully hardened. Pupal weight (henceforth 
WEIGHT) was $\log$ transformed to obtain a normal distribution. The overall difference between temperatures was small for this character. In summary four characters are analysed in this study: two wing pattern characters and two life history characters, one of each is plastic and the other not or only slightly so.

\section{Reaction norms}

Strictly speaking a reaction norm is the response of a single genotype to changes in the environment. Here, families were used to examine reaction norms rather than genotypes. Within a family only a limited number of genotypes is present, and taking the mean of the observed (full-sib) values calculates a mean genotypic value for that family (e.g. Scheiner \& Lyman, 1989). Calculating the means within environments and connecting them is then equivalent to constructing a reaction norm (Gebhardt \& Stearns, 1992, used the same method for inbred isofemale lines). This approach was used here and reaction norms were compiled by connecting the means of the families in the different temperatures.

\section{Calculation of genetic correlations}

Analysis of data was performed on experiments and sexes separately because means, variances and $h^{2} \mathrm{~s}$ varied between sexes and experiments, within temperatures (Windig, 1994). $r_{\mathrm{g}} \mathrm{s}$ were estimated for the four variables. SEASONAL FORM and THERMAL FORM are the first two components of a principal component analysis, so their overall phenotypic correlation must be zero. Correlations within temperatures and sexes can, however, be different from zero, and the same applies to $r_{\mathrm{g}} \mathrm{s}$. The expression of a character in different environments had to be measured on separate individuals, and therefore the usual statistical method for calculation of the genetical correlations (e.g. Falconer, 1989) is not applicable. They can, however, be calculated by correlation of the family means in two environments of families split over the two environments (Via, 1984, 1991):

$$
r_{\mathrm{g}}=\frac{C O V_{\mathrm{m} 1, \mathrm{~m} 2}}{\sqrt{\left(V_{\mathrm{m} 1}\right)\left(V_{\mathrm{m} 2}\right)}},
$$

where $C O V_{\mathrm{m} 1, \mathrm{~m} 2}$ is the covariance between the family means in the two environments, and $V_{\mathrm{m} 1}, V_{\mathrm{m} 2}$ are the variances of the family means in the two environments respectively. Such estimates will underestimate the $r_{\mathrm{g}}$, especially for small family sizes, because of the presence in the (co)variances of error (or within-family) variance, due to sampling error, in addition to the between-family variance:

$V_{\mathrm{m}}=V_{\text {Family }}+\left(\frac{1}{n}\right) V_{\text {Error }}$.

Several other ways of estimating reliable $r_{\mathrm{g}} \mathrm{s}$ exist (Via, 1984) but to attach standard errors to them is often a problem. Here a jackknife procedure (Holloway et al., 1990, 1994; Via, 1991) was used to calculate the $C O V_{\mathrm{g}}$ and $r_{\mathrm{g}}$ with standard errors. The jackknife is an iterative procedure (Arvesen \& Schmitz, 1970; Miller, 1974) and the calculations during each iteration are carried out using $n-1$ individuals (or $k-1$ groups of individuals). Here $r_{\mathrm{g}}$ was jackknifed with each family omitted once so that the total number of iterations was equal to the number of families. To take into account the difference in the number of individuals per family, individuals were regressed on the mean of their family in another temperature:

$r_{\mathrm{g} 1}=\frac{C O V_{\mathrm{i} 1, \mathrm{~m} 2}}{\sqrt{\left(V_{\mathrm{i} 1}\right)\left(V_{\mathrm{m} 2}\right)}} \quad$ and $r_{\mathrm{g} 2}=\frac{C O V_{\mathrm{m} 1, \mathrm{i} 2}}{\sqrt{\left(V_{\mathrm{m} 1}\right)\left(V_{\mathrm{i} 2}\right)}}$,

where $C O V_{\mathrm{i} 1, \mathrm{~m} 2}$ is the covariance of the individuals raised in one temperature with the means of their families raised in a second temperature, and $V_{\mathrm{i} 1}$ is the variance of individuals (= phenotypic variance) in the first temperature. $r_{\mathrm{g}} \mathrm{s}$ were $z$-transformed and normalized distributions of the jackknife estimates (Arvesen \& Schmitz, 1970). The estimates are generally similar but can be sometimes very different. For the regressions the final estimate used was the mean of the two regressions (Lam \& Calow, 1989; Holloway et al., 1993b).

Jackknifing is very sensitive to outliers, but it also provides a good opportunity to detect them (Devlin et al., 1975; Hinkley, 1978). Jackknifing usually produces a normal distribution of values after appropriate transformation. Here a family was considered to be an outlier and omitted from the calculation if it deviated by more than three standard deviations from the mean of all the estimates and if such a family was very small (only one or two members in one of the temperatures), i.e. when the estimation of the mean was probably corrupted by the small sample size. This led to the removal of only one or two families from each calculation (Table 1).

Though $r_{\mathrm{g}} \mathrm{s}$ between two characters within environments are normally estimated with an ANCOVA-like procedure (Falconer, 1989), here the same jackknife procedure was used as for the $r_{\mathrm{g}} \mathrm{s}$ across temperatures. These will give similar results to the ANCOVA-like procedures if the sample sizes are large (Via, 1984).

All $r_{\mathrm{g}} \mathrm{s}$ in this study are estimated from full-sibs. So they contain not only additive genetic effects but also nonadditive genetic, maternal and common environ- 
mental effects. These nonadditive effects are probably not important for the wing pattern characters SEASONAL FORM and THERMAL FORM (cf. Kingsolver \& Wiernasz, 1991). Common environmental effects might have somewhat more influence on DEVELOPMENT and WEIGHT, since these characters are more likely to be influenced by amounts and quality of food. These common environmental effects will be somewhat reduced because large families were raised in two or more cages. Common environmental effects will cause a higher proportion of the phenotypic correlations to be included in the $r_{\mathrm{g}} \mathrm{s}$ within temperatures. The $r_{\mathrm{g}} \mathrm{s}$ across temperatures can be decreased by common environmental effects because the common environmental effects across temperatures are uncorrelated; if the mean of a character for one family is increased in one temperature (e.g. by a relatively better food quality in its cage) it does not have to be increased in another temperature. So the $r_{g} \mathrm{~s}$ within temperatures, especially those with WEIGHT and DEVELOPMENT, will have to be interpreted with caution.

\section{Results}

SEASONAL FORM was more or less constant between $17^{\circ} \mathrm{C}$ and $20^{\circ} \mathrm{C}$ (Fig. 2; reaction norms for SEASONAL FORM vs. DEVELOPMENT also reflect the reaction norm of SEASONAL FORM on temperature, since DEVELOPMENT is strongly correlated to temperature). In the range $20-28^{\circ} \mathrm{C}$ there was a large increase in SEASONAL FORM. The $r_{\mathrm{g}} \mathrm{s}$ within seasonal form were neither strongly positive nor negative (Table 2). This corresponded to the form of the bundle of reaction norms with neither parallel reaction norms (for positive $r_{\mathrm{g}} \mathrm{s}$ ), nor reaction norms crossing at a single point (negative $r_{\mathrm{g}} \mathrm{s}$ ). In the reaction norms for DEVELOPMENT vs. temperature (inset Fig. 2) a point around which reaction norms cross is very clearly present just above $20^{\circ} \mathrm{C}$. Corresponding negative $r_{\mathrm{g}} \mathrm{s}$ were found between the higher and lower temperatures.

The slopes of the regression lines of SEASONAL FORM on DEVELOPMENT seemed to decrease with increasing development time: positive at $28^{\circ}$, flat

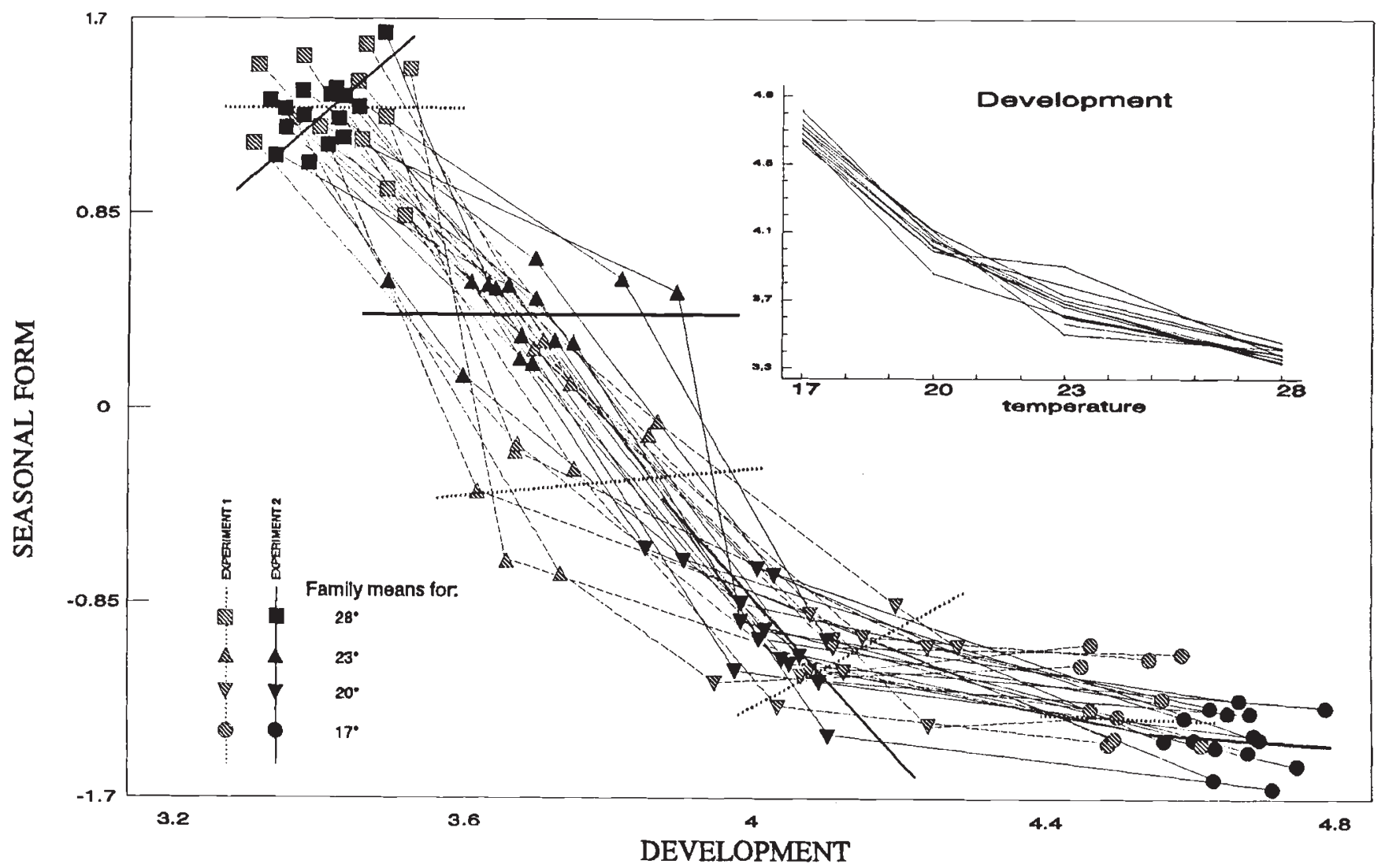

Fig. 2 Reaction norms for SEASONAL FORM-DEVELOPMENT time, for females. Symbols indicate means of families (hatched first experiment, solid black second). The means of the same family in different temperatures are connected, and thus form a reaction norm. Inset: reaction norms for DEVELOPMENT on temperature for females in the second experiment. 


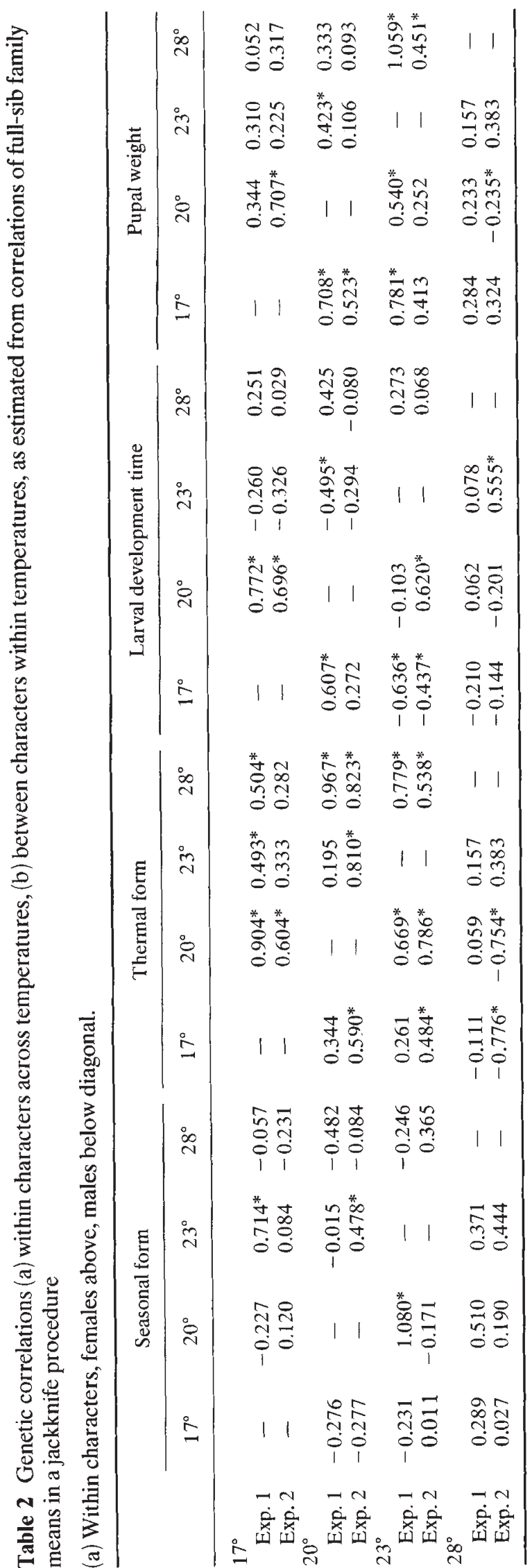

(b) Between characters, within temperatures.

\begin{tabular}{|c|c|c|c|c|}
\hline & $\begin{array}{l}\text { Males, } \\
\text { Exp. } 1\end{array}$ & $\begin{array}{l}\text { Females, } \\
\text { Exp. } 1\end{array}$ & $\begin{array}{l}\text { Males, } \\
\text { Exp. } 2\end{array}$ & $\begin{array}{c}\text { Females, } \\
\text { Exp. } 2\end{array}$ \\
\hline \multicolumn{5}{|c|}{ SEASONAL FORM-DEVELOPMENT } \\
\hline $17^{\circ}$ & -0.126 & -0.136 & 0.342 & -0.072 \\
\hline $20^{\circ}$ & $0.826^{*}$ & $0.439 *$ & -0.237 & $-0.753^{*}$ \\
\hline $23^{\circ}$ & $0.498^{*}$ & 0.414 & 0.214 & 0.094 \\
\hline $28^{\circ}$ & $0.639^{*}$ & -0.262 & $0.523^{*}$ & $0.532^{*}$ \\
\hline \multicolumn{5}{|c|}{ SEASONAL FORM-THERMAL FORM } \\
\hline $17^{\circ}$ & 0.123 & -0.134 & 0.013 & $-0.502^{*}$ \\
\hline $20^{\circ}$ & $-0.596^{*}$ & $-0.621^{*}$ & $-0.488^{*}$ & -0.179 \\
\hline $23^{\circ}$ & $-0.541 *$ & -0.003 & 0.006 & -0.278 \\
\hline $28^{\circ}$ & $0.733^{*}$ & $0.987^{*}$ & $0.679^{*}$ & $0.533^{*}$ \\
\hline \multicolumn{5}{|c|}{ THERMAL FORM-DEVELOPMENT } \\
\hline $17^{\circ}$ & -0.098 & -0.049 & 0.258 & 0.159 \\
\hline $20^{\circ}$ & -0.314 & 0.150 & $0.698^{*}$ & -0.061 \\
\hline $23^{\circ}$ & -0.289 & -0.454 & 0.037 & -0.069 \\
\hline $28^{\circ}$ & -0.002 & -0.437 & 0.479 & 0.270 \\
\hline \multicolumn{5}{|c|}{ SEASONAL FORM-WEIGHT } \\
\hline $17^{\circ}$ & $-0.512^{*}$ & -0.292 & 0.416 & -0.133 \\
\hline $20^{\circ}$ & -0.650 & -0.383 & -0.015 & -0.176 \\
\hline $23^{\circ}$ & $-0.683^{*}$ & -0.067 & -0.167 & -0.078 \\
\hline $28^{\circ}$ & -0.180 & -0.256 & -0.255 & 0.091 \\
\hline \multicolumn{5}{|c|}{ THERMAL FORM-WEIGHT } \\
\hline $17^{\circ}$ & 0.413 & $0.551^{*}$ & 0.367 & $0.485^{*}$ \\
\hline $20^{\circ}$ & $0.772^{*}$ & 0.119 & 0.323 & 0.252 \\
\hline $23^{\circ}$ & 0.241 & 0.046 & 0.030 & -0.143 \\
\hline $28^{\circ}$ & 0.117 & -0.085 & 0.041 & 0.221 \\
\hline \multicolumn{5}{|c|}{ DEVELOPMENT WEIGHT } \\
\hline $17^{\circ}$ & -0.205 & $-0.601^{*}$ & -0.133 & -0.510 \\
\hline $20^{\circ}$ & -0.405 & -0.221 & 0.201 & 0.029 \\
\hline $23^{\circ}$ & 0.051 & -0.284 & 0.243 & -0.211 \\
\hline $28^{\circ}$ & -0.207 & -0.072 & -0.366 & 0.178 \\
\hline
\end{tabular}

at $23^{\circ}$ and negative at $20^{\circ}$ in the second experiment (Fig. 2). In the first experiment positive slopes were found at $20^{\circ}$ at a somewhat longer average DEVELOPMENT than in the second experiment and just above the point where the reaction norms for DEVELOPMENT cross. At $17^{\circ}$ regression lines were flat. The single negative slope at $28^{\circ}$, for females in the first experiment, is caused by two outlying families with an average DEVELOPMENT but a low SEASONAL FORM. They are not outliers when the whole reaction norm is considered; they are somewhere in the middle of the bundle. These families were relatively large and thus were not removed as outliers from the regression analysis. Had they been removed the regression slope and genetic correlation would have been similar to the other estimates at $28^{\circ}$. The $r_{\mathrm{g}} \mathrm{s}$ between SEASONAL FORM and DEVELOPMENT showed sign changes, 
in the range from $28^{\circ}$ to $20^{\circ}$, corresponding to the reaction norms (Table 2 ).

Many reaction norms ran parallel for THERMAL FORM (Fig. 3). Some families had consistently lower values than average and others consistently higher over the whole environmental range. The $r_{\mathrm{g}} \mathrm{s}$ within THERMAL FORM, between temperatures, were nearly all strongly positive (Table 2 ). Only for males, in experiment 2, did negative correlations occur. The corresponding bundle of reaction norms indeed shows crossing reaction norms between the high and low parallel reaction norms.

In the graph for SEASONAL FORM-THERMAL FORM (Fig. 3) the males and females were clearly separated, females having a higher value for THERMAL FORM (thus being paler and larger). Within sexes the butterflies of the first experiment were generally above those of the second experiment. Regression lines in all groups, however, followed a similar pattern. The slopes changed from positive at $28^{\circ}$ to negative at $20^{\circ}$ (Fig. 3). At $17^{\circ}$ near-vertical lines seemed present. Slopes of regression lines, however, were not significantly different from zero, but this is expected for vertical lines. The $r_{\mathrm{g}} \mathrm{s}$ between THERMAL FORM and SEASONAL FORM showed a corresponding sign change from positive at $28^{\circ}$ to negative at $20^{\circ}$. There was no clear pattern in the reaction norms for THERMAL FORM on DEVELOPMENT and none of the $r_{\mathrm{g}} \mathrm{s}$ between THERMAL FORM and DEVELOPMENT were significant.

The bundle of reaction norms for WEIGHT was a horizontal band with some crossing over of reaction norms. Nearly all $r_{\mathrm{g}} \mathrm{s}$ were positive, but only some, mostly between neighbouring temperatures, were significant. There was a trend for the $r_{g} s$ to decrease when the temperatures were further apart (Table 2). The $r_{\mathrm{g}} \mathrm{s}$ for WEIGHT with the other characters were similar in different temperatures (Table 2): negative for WEIGHT-DEVELOPMENT and WEIGHT-SEASONAL FORM and positive for

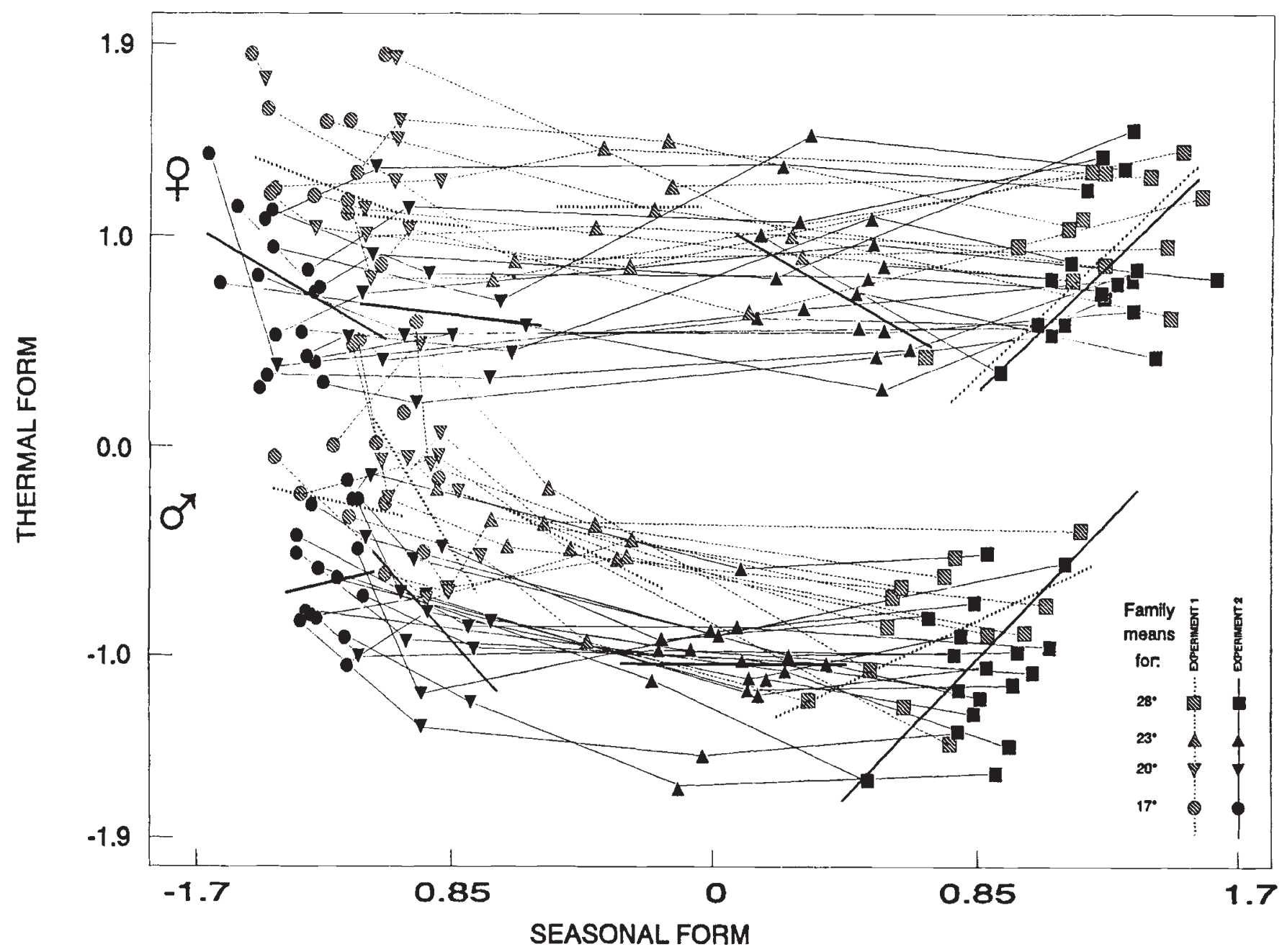

Fig. 3 Reaction norms for SEASONAL FORM-THERMAL FORM. Symbols as Fig. 2. 
WEIGHT-THERMAL FORM. Only some of these were significant.

\section{Discussion}

This study had the objective to analyse a system which is adaptively plastic, with the help of reaction norms and genetic correlations $\left(r_{\mathrm{g}} \mathrm{s}\right)$. It found that each character had its own specific form for its bundle of reaction norms (question 1 of the Introduction). Consequently the $r_{\mathrm{g}} \mathrm{s}$ within characters, across temperatures (question 2) differed for the four characters and ranged from negative for DEVELOPMENT, around zero for SEASONAL FORM, to positive for WEIGHT and THERMAL FORM. Most $r_{\mathrm{g}} \mathrm{s}$ between characters, within temperatures, were not significant (question 3), except for DEVELOPMENT-SEASONAL FORM and THERMAL FORM-SEASONAL FORM which changed sign from positive at $28^{\circ}$ to negative at $20^{\circ}$. Reaction norms and $r_{\mathrm{g}} \mathrm{s}$ were generally consistent with each other (question 4 ).

From a theoretical point of view absence of strong positive correlations within a character together with changes of $r_{\mathrm{g}} \mathrm{s}$ between two characters are generally expected in plastic characters (Stearns et al., 1991). Only when their reaction norms run parallel over the whole environmental range will this not be the case. For nonplastic characters the same may apply. The only difference from plastic characters is that on average, over all genotypes, the phenotype remains the same over the whole environmental range. Individual genotypes may show (limited) plasticity over (part of) their environmental range in such a way that the rank order of the genotypes changes.

Most studies that have analysed reaction norms have found bands in which crossing-over occurs, but not at one specific point (e.g. Mazer \& Schick, 1991; Rawson \& Hilbish, 1991; Gebhardt \& Stearns, 1992). Consequently nearly all $r_{\mathrm{g}} \mathrm{s}$ across environments reported in the literature are positive (e.g. Via, 1984; Wade, 1990; Platenkamp \& Shaw, 1992; Ebert et al., 1993; Etges, 1993; Thomas \& Bazzaz, 1993; Andersson \& Shaw, 1994) and negative $r_{\mathrm{g}} \mathrm{s}$ are exceptional (e.g. Via, 1991). This indicates that genes influence a character in different environments in a similar way, and that selection in one environment has a similar effect in a different environment. For this study the same applies to THERMAL FORM and WEIGHT. For SEASONAL FORM $r_{\mathrm{g}} \mathrm{s}$ were low and this suggests that selection in one season has little effect on the expression of the phenotype in the other season. For DEVELOPMENT the negative $r_{\mathrm{g}} \mathrm{s}$ imply that selection in one season will have the opposite effect in the other season.
Many studies, mainly in Drosophila, report a sign change in $r_{\mathrm{g}} \mathrm{s}$ across environments (Murphy et al., 1983; Service \& Rose, 1985; Mukai, 1988; Newman, 1988; Gebhardt \& Stearns, 1988, 1992). This study found two out of six correlations with sign changes across environments. Reaction norms for wing pattern characters in B. anynana generally do not run parallel, and genetic variation in slopes of the reaction norms for SEASONAL FORM is also present (Windig, 1994) so sign changes were not unexpected from this point of view.

To clarify the sign change in the $r_{\mathrm{g}}$ for SEASONAL FORM-DEVELOPMENT a simple graphical model with reaction norms for a limited number of genotypes was made (Fig. 4). In the model the negative $r_{\mathrm{g}} \mathrm{s}$ within DEVELOPMENT can be seen because the genotypes that have relatively fast development times at high temperatures are relatively slow at low temperatures. Because there is no differentiation in SEASONAL FORM at $23^{\circ}$ and $17^{\circ}$ the $r_{\mathrm{g}} \mathrm{s}$ around zero with these temperatures are also explained. The instability of the $r_{\mathrm{g}} \mathrm{s}$ at $20^{\circ}$ can be explained because the reaction norms cross around this temperature and at the same time they flatten off. So although the reaction norms are not linear, crossing of reaction norms leads to a sign change.

A similar model was made for THERMAL FORM-SEASONAL FORM correlations (Fig. 5). The positive $r_{\mathrm{g}} \mathrm{s}$ for THERMAL FORM are reflected by the fact that the rank of the genotypes is the same for each temperature. At intermediate values for SEASONAL FORM the values for THERMAL FORM are identical for all genotypes in this model, explaining the horizontal regression lines and insignificant correlations at $23^{\circ}$. Only a slight modification, letting the reaction norms cross instead of touch each other at intermediate temperatures, is needed to get negative $r_{\mathrm{g}} \mathrm{s}$. In this model a sign change in $r_{\mathrm{g}} \mathrm{s}$ can be explained with more or less parallel reaction norms in one of the characters.

\section{Genetic correlations, developmental and functional explanations}

Genetic correlations between characters will be strong if they are developmentally or functionally related. Thus developmental and/or adaptive processes might explain the observed pattern of $r_{\mathrm{g}} \mathrm{s}$. On a developmental level characters that share part of their developmental pathway will show stronger $r_{\mathrm{g}} \mathrm{s}$. At a functional level stronger $r_{\mathrm{g}} \mathrm{s}$ will evolve if an increase in one character is only adaptive when another character is increased (positive correlations) or decreased (negative correlations) simultaneously. When characters are considered in different environments their $r_{\mathrm{g}} \mathrm{s}$ will 
Fig. 4 Graphical model explaining the observed pattern for genetic correlations between DEVELOPMENT and SEASONAL FORM. The two lines indicate the two most extreme genotypes. Intermediate reaction norms are left out, except for one, for clarity.

Points indicate DEVELOPMENT and SEASONAL FORM within one environment (e.g. temperature). One extreme genotype reacts more on temperature differences in the lower temperatures, the other on differences in the higher temperatures.

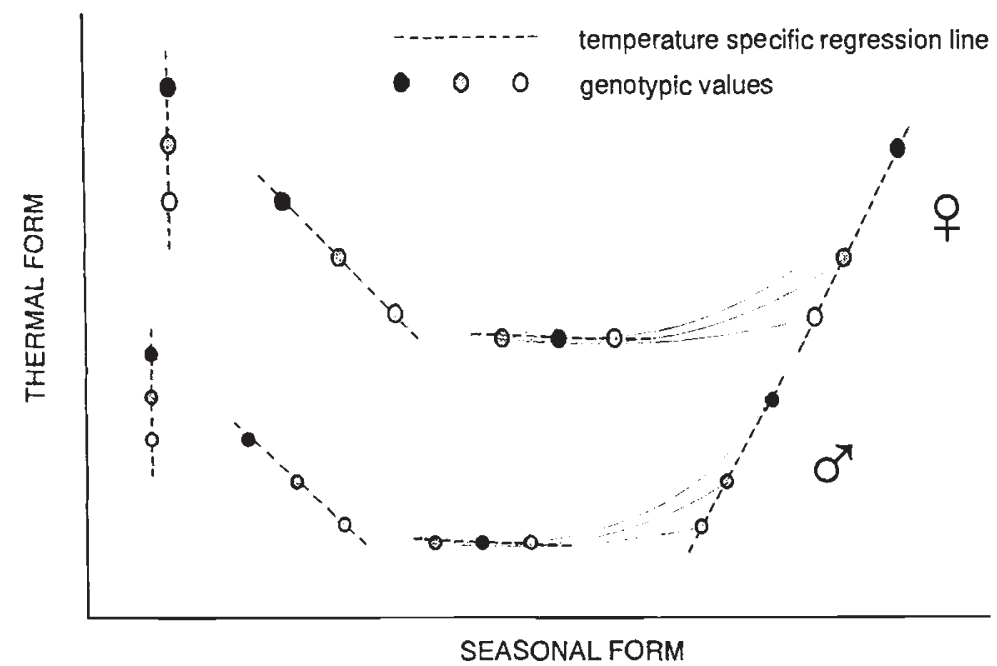

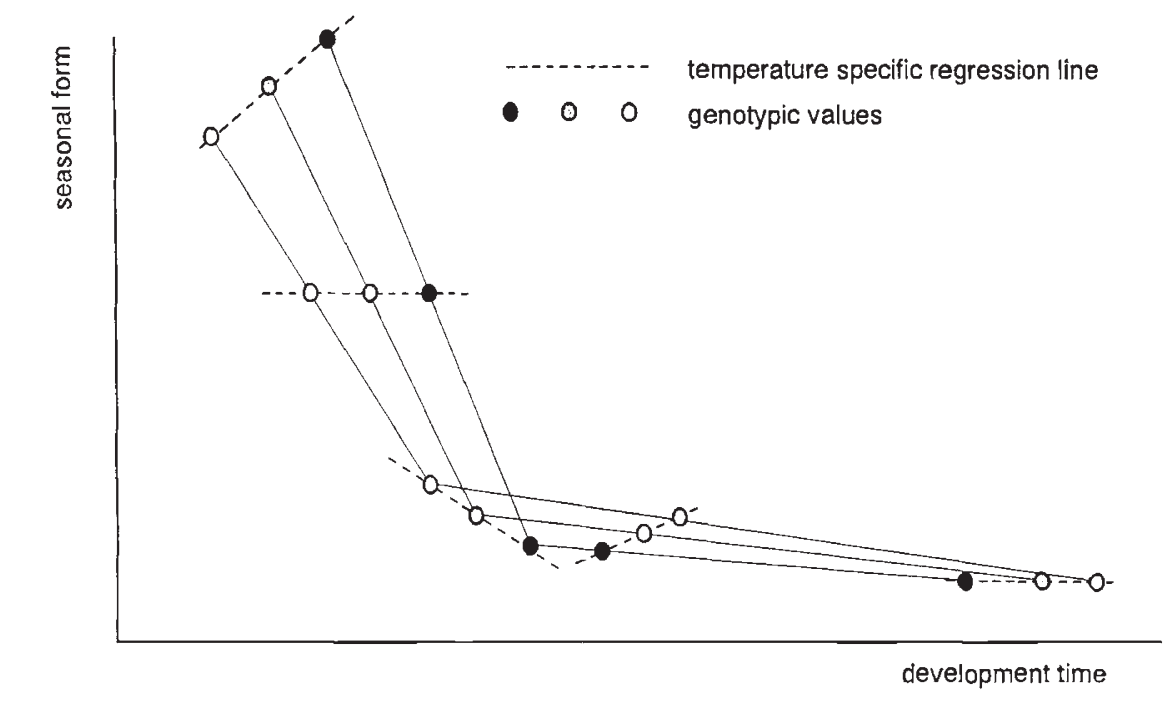

Fig. 5 Graphical model explaining the observed pattern for genetic correlations between THERMAL FORM and SEASONAL FORM. Explanation as Figure 4. change over environments if (variation in) their developmental pathways and/or their functions differ in the environments. In plastic characters this will generally be the case.

If functions of a character change completely over environments low $r_{\mathrm{g}} \mathrm{s}$ within a character can be expected. This allows the different expressions of such a character to evolve relatively independently. This is exactly what can be seen in SEASONAL FORM. The observed low $r_{\mathrm{g}} \mathrm{s}$ are also in agreement with the observed substantive amounts of additive variation for plasticity in this character (Windig, 1993).

A developmental relationship between the expression of a character in two environments is obvious; after all it is the same character. Crucial for the $r_{\mathrm{g}} \mathrm{s}$ is whether flexibility exists in the developmental pathway. It may well be, for example, in THERMAL FORM that there is a polymorphism for pigments which are produced independently of larval temperature, explaining the genotypes that are darkest or lightest throughout the environmental range. In DEVELOPMENT $r_{\mathrm{g}} \mathrm{s}$ are positive between neighbouring temperatures but negative between the more distant temperatures. Genotypes with enzymes that have their kinetic optima at different temperatures (e.g. Watt, 1977; Watt et al., 1983) might explain such a pattern.

The $r_{\mathrm{g}}$ between two characters will change over environments if a corresponding change in function or development occurs. A developmental or functional relationship between DEVELOPMENT and THERMAL form is difficult to envisage. The absence of significant $r_{\mathrm{g}} \mathrm{s}$ is then possibly the result of the absence of any functional or developmental relationship. 
In life history theory, growth rate and size are traits involved in an energy trade-off (Stearns, 1992). Such trade-offs are believed to lead to the evolution of negative $r_{\mathrm{g}}$ s (Lande, 1982; Rose, 1984). Since length of DEVELOPMENT time is opposite to growth rate, a positive genetic correlation is expected for WEIGHT-DEVELOPMENT. Negative $r_{\mathrm{g}} \mathrm{s}$ were, however, found in all temperatures. Though $r_{\mathrm{g}} \mathrm{s}$ consistent with the operation of trade-offs have sometimes been found in other studies (e.g. Holloway et al., 1990; Rose \& Charlesworth, 1981; Soliman, 1982), this is not always so (e.g. Stearns, 1983; Murphy et al., 1983; Bell, 1984a,b; Holloway et al., 1993b). Several authors have suggested why unexpected $r_{\mathrm{g}} \mathrm{s}$ are sometimes found (Service \& Rose, 1985; van Noordwijk \& de Jong, 1986; Holloway et al., 1990; Charlesworth, 1990). No definite conclusions can be drawn from this study since many of the negative $r_{\mathrm{g}} \mathrm{s}$ were not significant, and the possibility of common environmental and maternal effects having influenced the $r_{\mathrm{g}} \mathrm{s}$ exists. An experimental design better suited to evaluate life history traits is needed to demonstrate whether the negative $r_{\mathrm{g}}$ s found here for WEIGHT-DEVELOPMENT really exist.

WEIGHT and THERMAL FORM are characters that are developmentally related. Both are, at least partly, measurements of body size (Windig, 1993). Apart from size THERMAL FORM is also determined by the darkness of the wings. Nevertheless, THERMAL FORM and WEIGHT are clearly developmentally related and positive correlations are to be expected between the two characters. Indeed nearly all correlations found between them are positive. The fact that only a few values are significantly different from 0 is probably more the result of the weakness of power of the test, than any reflection of a real absence of correlation.

A trade-off between SEASONAL FORM and DEVELOPMENT might explain the positive $r_{\mathrm{g}} \mathrm{s}$ found at the higher temperatures. In the wet season directional selection for DEVELOPMENT is expected; faster developing individuals can probably foster more offspring. If the production of a wet wing pattern is costly, for example in energetic terms, and a dry wing pattern is not, a trade-off with growth rate might result in positive correlations between SEASONAL FORM and DEVELOPMENT in the wet season, and an absence of trade-offs in the dry season. It is, however, doubtful if the production of a wet season wing pattern is costly. French \& Brakefield (1992) have demonstrated that the production of eyespots in $B$. anynana can be induced or inhibited by simple cautery of some cells on the wing epidermis in the pupal stage.
Phenotypic correlations between SEASONAL FORM and DEVELOPMENT are strongly negative within temperatures (Windig, 1992, 1994). A simple physiological model can explain this: the amount of a certain chemical at the end of the larval stage determines the 'wetness' of the wing pattern of a butterfly, and a constant fraction of this chemical is synthesized or denatured each day in the larval stage. If there are differences in the rate of production (denaturation) of the chemical or in the initial amount this will lead to variation in SEASONAL FORM. A lower rate of production (denaturation) that is genetically linked to a faster development can explain the observed significant $r_{\mathrm{g}} \mathrm{s}$. A better understanding of the physiology is needed to explain fully the relation between SEASONAL FORM and DEVELOPMENT, and possibly the observed $r_{\mathrm{g}} \mathrm{s}$.

At $28^{\circ}$ a clear negative relationship exists between SEASONAL FORM and THERMAL FORM. This might reflect a trade-off: butterflies can either develop into a form that is suited to good fliers: small with dark wings (optimal pattern in males), or a form that suits better motionless (e.g. egg-laying) butterflies (optimal in females). In dark wings a pattern with a white band and large eyespots etc. might interfere with the thermal requirements, whereas in a large, pale wing large eyespots might be more effective and more important in motionless butterflies. In the dry season, butterflies might be either optimized for survival in the dry period (large and dry forms), or optimized for reproduction in the wet period (small and wet forms). This might explain the negative $r_{\mathrm{g}} s$ between SEASONAL and THERMAL FORM in the lower temperatures as well as the negative $r_{g} s$ between WEIGHT and SEASONAL FORM.

\section{Concluding remarks}

The argument of Stearns et al. (1991), that $r_{\mathrm{g}}$ themselves are not interesting but that they might indicate the underlying developmental and functional relationships between characters (see also Cheverud, 1984), is emphasized by this study. Physiological (DEVELOPMENT-SEASONAL FORM) or functional (SEASONAL FORM-THERMAL FORM) processes can explain the observed $r_{\mathrm{g}} \mathrm{s}$ and their sign changes across environments. Evaluation of the fitnesses of different genotypes in the field is needed, on the one hand to determine whether selection could have led to the observed $r_{\mathrm{g}} \mathrm{s}$, and on the other to determine how correlations across as well as within environments influence the outcome of selection. Better knowledge of physiological processes is also needed to understand some $r_{\mathrm{g}} \mathrm{s}$, including those between DEVE- 
LOPMENT and SEASONAL FORM at different temperatures. It will only be possible to understand fully evolutionary processes in the field if we understand the development and function of the characters under study.

\section{Acknowledgements}

I am grateful to Paul Brakefield and Graham Holloway for many suggestions and helpful comments during the experiments and analysis. Graham was especially helpful with the calculations of the genetic correlations. Their comments on the manuscript together with those of Gerdien de Jong were also very useful. Bert de Winter, Diana Lockhorst and Marianne van Genderen helped raise all the very hungry larvae, for which Els Schlatmann, Wim Kanters and Bert de Winter raised the food plants.

\section{References}

ANDERSSON, S. AND SHAW, R. G. 1994. Phenotypic plasticity in Crepis tectorum (Asteraceae): genetic correlation across light regimens. Heredity, 72, 113-125.

ARVESEN, J. M. AND SCHMITZ, T. H. 1970. Robust procedures for variance components problems using the jackknife. Biometrica, 26, 677-686.

BELL, G. 1984a. Measuring the cost of reproduction. I. The correlation structure of the life table of a plankton rotifer. Evolution, 38, 300-313.

BELL, G. 1984b. Measuring the cost of reproduction. II. The correlation structures of the life tables of five freshwater invertebrates. Evolution, 38, 314-326.

BRAKEFIELD, P. M. AND LARSEN, T. B. 1984. The evolutionary significance of dry and wet season forms in some tropical butterflies. Biol. J. Linn. Soc., 22, 1-12.

BRAKEFIELD, P. M. AND REITSMA, N. 1991. Phenotypic plasticity, seasonal climate and the population biology of Bicyclus butterflies in Malawi. Ecol. Entomol., 10, 291-303.

CHARLESWORTH, B. 1990. Optimization models, quantitative genetics, and mutation. Evolution, 44, 520-538.

CHEverud, J. M. 1984. Quantitative genetics and developmental constraints on evolution by selection. J. Theor. Biol., 110, 155-171.

Condamin, M. 1973. Monographie du genre Bicyclus (Lepidoptera Satyridae). Mem. Inst. Fond. Afr. Noire, 88, 1-324.

COWLEY, D. E. AND ATChley, w. R. 1990. Development and quantitative genetics of correlation structure among body parts of Drosophila melanogaster. Am. Nat., 135, 242-268.

DEVLIN, S. J., GNADESIKAN, R. AND KETTERING, J. R. 1975. Robust estimation and outlier detection with correlation coefficients. Biometrika, 62, 531-545.

DENNIS, R. L. H. 1993. Butterflies and Climate Change. Manchester University Press, Manchester, U.K.

DINGLE, H., EVANS, K. E. AND PALMER, J. o. 1988. Responses to selection among life history traits. Evolution, 42, 79-92.
EBERT, D., YAMPOLSKY L. AND VAN NOORDWIJK, A. J. 1993. Genetics of life history in Daphnia magna. II. Phenotypic plasticity. Heredity, 70, 344-352.

ETGES, W. J. 1993. Genetics of host-cactus response and lifehistory evolution among ancestral and derived populations of cactophilic Drosophila mojavensis. Evolution, 47, $750-767$.

FALCONER, D. S. 1989. Introduction to Quantitative Genetics, 3rd end. Longman, London.

FRENCH, V. AND BRAKEFIELD, P. M. 1992. The development of eyespot patterns on butterfly wings: morphogen sources or sinks? Development, 116, 103-109.

GEBHARDT, M. D. AND STEARNS, S. C. 1988. Reaction norms for developmental time and weight at eclosion in Drosophila mercatorum. J. Evol. Biol., 1, 335-354.

GEBHARDT, M. D. AND STEARNS, S. C. 1992. Phenotypic plasticity for life history traits in Drosophila melanogaster. II. Effect of the environment on genetic parameters. Gen. Res., 60, 87-101.

GIESEL, J. T., MURPHY, P. A. AND MANLOVE, M. N. 1982. The influence of temperature on genetic interrelationships of life history traits in a population of Drosophila melanogaster: what tangled data sets we weave. Am. Nat., 119, 464-479.

GROETERS, F. R. AND DINGLE, H. 1987. Genetic and maternal influences on life history plasticity in response to photoperiod by milkweed bugs (Oncopeltus fasciatus). Am. Nat., 129, 332-346.

HINKLEY, D. V. 1978. Improving the jackknife with special reference to correlation estimation. Biometrika, 65, 13-21.

HOLLOWAY, G. J., POVEY, S. R. AND SIBLY, R. M. 1990. The effect of new environment on adapted genetic architecture. Heredity, 64, 323-330.

HOLLOWAY, G. J., BRAKEFIELD, P. M. AND KOFMAN, S. 1993a. The genetics of wing pattern elements in the polyphenic butterfly Bicyclus anynana. Heredity, 70, 179-186.

HOLLOWAY, G. J., DE JONG, P. W. AND OTTENHEIM, M. 1993b. The quantitative genetics and cost of defence in the 2-spot ladybird (Adalia bipunctata) and the effect of sex on the additive genetic variance/covariance matrix. Evolution 47, 1229-1239.

HUGHES, D. J. 1992. Genotype-environment interactions and relative clonal fitness in a marine bryozoan. J. Anim. Ecol., 61, 291-306.

de JONG, G. 1989. Phenotypically plastic characters in isolated populations. In: Fontdevila, A. (ed.) Evolutionary Biology of Transient Unstable Populations, pp. 3-18. Springer, Heidelberg.

de JONG, G. $1990 \mathrm{a}$. Quantitative genetics of reaction norms. $J$. Evol. Biol., 3, 447-468.

de JONG, G. $1990 \mathrm{~b}$. Genotype by environment interaction and the genetic covariance between environments: multilocus genetics. Genetica, 81, 171-177.

KINGSOLVER, J. G. AND WiERNASZ, D. C. 1991. Development, function and the quantitative genetics of wing melanin pattern in Pieris butterflies. Evolution, 45, 1480-1492.

LAM, P. K. S. AND CALOW, P. 1989. Intraspecific life-history variation in Lymnea peregra (Gastropoda: Pulmonata). II. 
Environmental or genetic variance? J. Anim. Ecol., 58, 589-602.

LANDE, R. 1982. A quantitative genetic theory of life history evolution. Ecology, 63, 607-615.

LOFSVOLD, D. 1986. Quantitative genetics of morphological differentiation in Peromyscus. I. Tests of homogeneity of genetic covariance structure among species and subspecies. Evolution, 20, 559-573.

MAZER, S. J. AND SCHICK, C. T. 1991. Constancy of population parameters for life history and floral traits in Raphanus sativus L. I. Norms of reaction and the nature of genotype by environment interactions. Heredity, 67, 143-156.

MILLER, R. G. 1974. The jackknife - a review. Biometrika, 61, $1-15$.

MUKAI, T. 1988 Genotype-environment interaction in relation to the maintenance of genetic variability in populations of Drosophila melanogaster. In: Weir, B. S., Eisen, E. J., Goodman, M. J. and Namkoong, G. (eds) Proceedings of the Second International Conference on Quantitative Genetics, pp. 21-31. Sinauer, Sunderland, MA.

MURPHY, P. A., GIESEL, T. A. AND MANLOVE, M. N. 1983. Temperature effects on life history variation in Drosophila simulans. Evolution, 37, 1181-1192.

NEWMAN, R. A. 1988. Adaptive plasticity in development of Scaphiopus couchii tadpoles in desert ponds. Evolution, 42, 671-678.

van NOORDWIJK, A. J. AND de JONG, G. 1986. Acquisition and allocation of resources: their influence on life history tactics. Am. Nat., 128, 137-142.

PLATENKAMP, G. A. J. AND SHAW, R. G. 1992. Environmental and genetic constraints on adaptive population differentiation in Anthoxanthum odoratum. Evolution, 46, 341-352.

RAWSON, P. D. AND HILBISH, T. H. 1991. Genotype-environment interaction for juvenile growth in the hard clam Mercenaria mercenaria (L.). Evolution, 45, 1924-1935.

RoSE, M. R. 1984. Genetic covariance in Drosophila life history: untangling the data. Am. Nat., 123, 565-569.

ROSE, M. R. AND CHARLESWORTH, B. 1981. Genetics of life history in Drosophila melanogaster. I. Sib analysis of adult females. Genetics, 97, 187-196.

SCHEINER, S. M. AND LYMAN, R. F. 1989. The genetics of phenotypic plasticity. I. Heritability. J. Evol. Biol., 2, 95-107.

SCHLichting, C. D. 1976. The evolution of phenotypic plasticity in plants. Ann. Rev. Ecol. Syst., 17, 667-693.

SERVICE, P. M. AND ROSE, M. R. 1985. Genetic covariation among life history components: the effect of novel environments. Evolution, 39, 943-945.

SOLiman, M. H. 1982. Directional and stabilizing selection for developmental time and correlated response in reproductive fitness in Tribolium castaneum. Theor. Appl. Gen., 63, 111-116.
STEARNS, S. C. 1983. The genetic basis of differences in life history traits among six populations of mosquito fish (Gambusia affinis) that shared common ancestors in 1905. Evolution, 37, 618-627.

StEARns, s. C. 1992. The Evolution of Life History. Oxford University Press, New York.

STEARNS, S. C., de JONG, G. AND NEWMAN, R. A. 1991. The effects of phenotypic plasticity on genetic correlations. Trends Ecol. Evol., 6, 122-126.

THOMAS, S. C. AND BAZZAZ, F. A. 1993. The genetic component in plant size hierarchies: norms of reaction to density in a Polygonum species. Ecol. Monogr., 63, 231-249.

THOMPSON, J. D. 1991. Phenotypic plasticity as a component of evolutionary change. Trends Ecol. Evol., 6, 246-249.

VIA, S. 1984. The quantitative genetics of polyphagy in an insect herbivore. II. Genetic correlations in larval performance within and among host plants. Evolution, 38, 896-905.

vIA, s. 1991. The genetic structure of hostplant adaptation in a spatial patchwork: demographic variability among reciprocally transplanted clones. Evolution 45, 827-852.

VIA, S. AND LANDE, R. 1985. Genotype environment interaction and the evolution of phenotypic plasticity. Evolution, 39, 505-522.

WADE, M. J. 1990. Genotype-environment interaction for climate and competition in a natural population of flour beetles Tribolium castaneum. Evolution, 44, 2004-2011.

WATT, w. B. 1977 . Adaptation at specific loci. I. Natural selection of phosphoglucose isomerase of Colias butterflies: biochemical and population aspects. Genetics, 87, 177-194.

WATT, W. B., CASSIN, R. C. AND SWAN, M. S. 1983. Adaptation at specific loci. III. Field behaviour and survivorship differences among Colias PGI genotypes are predictable from in vitro biochemistry. Genetics, 103, 725-739.

WINDIG, J. J. 1991. Quantification of butterfly wing patterns using an image analyser. J. Res. Lepid., 30, 82-94.

WINDIG, J. J. 1992. Seasonal polyphenism in Bicyclus safitza: a continuous reaction norm. N. J. Zool. 42, 583-594.

wINDIG, J. J. 1993. The Genetic Background of Plasticity in Wing Pattern of Bicyclus Butterflies. Ph.D. Thesis, University of Leiden.

WINDIG, J. J. 1994. Reaction norms and the genetic basis of phenotypic plasticity in wing pattern of the butterfly Bicyclus anynana. J. Evol. Biol., (in press).

WINDIG, J. J., BRAKEFIELD, P. M., REITSMA N., AND WILSON J. G. M 1994. Seasonal polyphenism in the wild: survey of wing patterns in five species of Bicyclus butterflies in Malawi. Ecol. Entomol., (in press).

ZUBERI, M. I. AND GALE, J. S. 1976. Variation in wild populations of Papaver dubium. X. Genotype-environment interaction associated with differences in soil. Heredity, 36, 359-368. 